\title{
Investigation of the Total Flow Rates in Oil Natural Transformer Retrofilling Scenarios
}

\section{Document Version}

Accepted author manuscript

Link to publication record in Manchester Research Explorer

\section{Citation for published version (APA):}

Zhang, X., Wang, Z., Liu, Q., Gyore, A., \& Rapp, K. (2019). Investigation of the Total Flow Rates in Oil Natural Transformer Retrofilling Scenarios. In International Conference on Dielectric Liquids (ICDL)

https://ieeexplore.ieee.org/stamp/stamp.jsp?arnumber=8796546

\section{Published in:}

International Conference on Dielectric Liquids (ICDL)

\section{Citing this paper}

Please note that where the full-text provided on Manchester Research Explorer is the Author Accepted Manuscript or Proof version this may differ from the final Published version. If citing, it is advised that you check and use the publisher's definitive version.

\section{General rights}

Copyright and moral rights for the publications made accessible in the Research Explorer are retained by the authors and/or other copyright owners and it is a condition of accessing publications that users recognise and abide by the legal requirements associated with these rights.

\section{Takedown policy}

If you believe that this document breaches copyright please refer to the University of Manchester's Takedown Procedures [http://man.ac.uk/04Y6Bo] or contact uml.scholarlycommunications@manchester.ac.uk providing relevant details, so we can investigate your claim.

\section{OPEN ACCESS}




\section{Investigation of the Total Flow Rates in Oil Natural Transformer Retrofilling Scenarios}

\author{
Xiang Zhang, Zhongdong Wang, Qiang Liu \\ School of Electrical and Electronic \\ Engineering \\ The University of Manchester \\ Manchester, UK \\ zhongdong.wang@manchester.ac.uk
}

\author{
Attila Gyore \\ Technical Department \\ $M \&$ I Materials Ltd \\ Manchester, UK \\ AttilaGyore@mimaterials.com
}

\author{
Kevin Rapp \\ Dielectric Liquids \\ Cargill, Incorporated \\ Minnetonka, US \\ Kevin_Rapp@cargill.com
}

\begin{abstract}
Retrofilling transformers with a new liquid has been considered as an option for life extension and/or uprating purposes. The determination of the new total liquid flow rate is of vital importance in assessing the effect of retrofilling on flow and temperature distributions in the winding, especially for ON transformers. This paper presents the determination of flow rate ratios for four liquids-a mineral oil, a GTL oil, a synthetic ester and a natural ester-in $O N$ transformer retrofilling scenarios. Flow rate ratios among different liquids are provided for a simplified condition of linear radiator oil temperature variation. For a more realistic exponential radiator oil temperature variation, the detailed transformer geometric information is needed to estimate the total flow rate. In addition, a hydraulic winding network model is established to prove that "minor pressure losses" due to change of flow directions is indeed minor for $\mathrm{ON}$ transformer liquid flow conditions, justifying neglecting the minor losses in the deduction of the total liquid flow rate.
\end{abstract}

Keywords-ester, flow rate, GTL, mineral oil, retrofilling, transformer

\section{INTRODUCTION}

Liquid-immersed power transformers are the most common type in the power networks. The liquid serves as electrical insulation and as a dielectric coolant. Conventionally, mineral oil has been used as the dielectric coolant. Nowadays, alternative liquids, such as gas-toliquid (GTL) oil, synthetic ester and natural ester liquids are increasingly used for the advantage of purity for GTL and higher fire safety and biodegradability for synthetic and natural ester liquids. One of the main requirements of these liquids is the thermohydraulic performance, which influences the highest temperature in the winding. It is usually referred to as the hotspot temperature, which dictates the highest thermal ageing rate of the cellulose insulation in the transformer $[1,2]$.

Changing the liquid type requires reviewing the transformer design to ensure it can accommodate to the new liquid properties. However, scenarios can arise when a transformer is retrofilled with an alternative liquid for the purposes of life extension and/or uprating of the transformer. Therefore, investigation of the thermohydraulic behaviour of the liquids is of vital importance for the implementation of the retrofilling.

Thermohydraulic behaviour of different liquids in disctype windings for OD and ON cooling modes are presented in [3-6] for given total flow rates in the winding. For OD cooling modes, the total flow rate can be adjusted by choosing different pumps. The flow and temperature distributions are found to be mainly controlled by the
Reynolds number $(R e)$ at the winding pass inlet [3, 5]. For ON cooling modes, flow and temperature distributions in the winding are found mainly controlled by $R e$ and the Richardson number (Ri) [4, 6]. These controlling parameters are closely linked to the total liquid flow rate in the winding, which is dictated by the thermosiphon force and the pressure drop in the whole cooling loop. Therefore, the determination of the total flow rate in an $\mathrm{ON}$ transformer is the key to understand its thermohydraulic behaviour, especially when different liquids are involved.

The total liquid flow rate in an $\mathrm{ON}$ transformer is investigated experimentally and theoretically in $[7,8]$. The total liquid flow rate is found to be approximately proportional to the square root of the total power loss in the winding and the square root of the thermal head, which is the distance between the centre point of the radiator and the centre point of the winding. The flow rate ratios for different liquids are determined in [4, 6] with assumptions of linear temperature distribution along the radiator panels and negligible "minor losses" arising from the change of flow directions in the cooling loop.

In this paper, the determination of the total liquid flow rate for ON transformers in a steady state is elaborated with the justification of neglecting "minor losses" provided by establishing a hydraulic winding network model. Section II is the elaboration of ON flow rate determination. Section III presents the hydraulic network model and the justification of neglecting "minor losses", followed by conclusion in section IV.

\section{DETERMINATION OF TOTAL LIQUID FLOW RATE IN ON COOLING MODES}

The total liquid flow rate in an $\mathrm{ON}$ transformer in a steady state is determined by the driving pressure arising from thermosiphon force and the pressure drop in the complete cooling loop. Equalizing the two pressures leads to the steady state flow rate.

\section{A. Thermal Driving Force}

When the overall flow in the cooling loop is treated as a one-dimensional flow, the thermal driving force can be expressed as the loop line integral:

$p_{T}=\oint_{l} \rho \cdot \vec{g} d \vec{l}$

where $p_{T}$ stands for the thermal driving pressure, $\rho$ for liquid density, $g$ for gravitational acceleration, $l$ for the integral path. 
Since heat transfer occur mainly in the winding and the radiator, oil temperature variation in the pipe can be ignored. In addition, the power loss in the winding is mainly composed of resistive loss and it is quasi-uniform along the winding. Therefore oil temperature variation in the winding can be treated as linear. Oil temperature variation in the radiator can be simplified as a linear variation as shown by the red dash line in Fig. 1 (b). However, a more realistic exponential radiator oil temperature profile as shown by the red solid line in Fig. 1 (b) can be obtained by assuming a constant heat transfer coefficient on the radiator surface and a constant ambient temperature. The thermal driving force for the two radiator oil temperature profiles are given in the following subsections.

\section{a) Linear Radiator Oil Temperature Profile}

Under the assumption of linear oil temperature variation in the radiator and linear variation of oil density with temperature, the thermal driving force in (1) can be approximated to be $[4,7]$ :

$p_{T}=\rho_{0} \cdot g \cdot \beta \cdot \Delta T \cdot \Delta H$

where $\rho_{0}$ is the reference density at ambient temperature, $\beta$ is the thermal expansion coefficient, $\Delta T$ is oil temperature difference over the winding or radiator, and $\Delta H$ is the thermal head.

\section{b) Exponential Radiator Oil Temperature Profile}

Assuming the heat transfer coefficient per unit length on the radiator surface is $h_{L}$, the ambient temperature is a constant, $T_{a m b}$, the winding outlet or radiator inlet temperature is $T_{l}$, oil specific heat is a constant, $c_{p}$, and the mass flow rate through the radiator is $\dot{m}$, we have the energy conservation equation for oil in the radiator:

$h_{L}\left(T-T_{a m b}\right) d x=-\dot{m} c_{p} d T$

where $x$ is the distance from the top of the radiator to the location being analyzed in (3).

The solution of (3) is an exponential equation

$$
T-T_{a m b}=\left(T_{1}-T_{a m b}\right) \cdot \exp \left(-\frac{h_{L}}{\dot{m} c_{p}} \cdot x\right)
$$

The oil density varies linearly with temperature, so we have exponential oil density variation:

$$
\begin{aligned}
\rho & =\frac{\rho_{0}}{1+\beta\left(T-T_{a m b}\right)} \approx \rho_{0}\left(1-\beta\left(T-T_{a m b}\right)\right) \\
& =\rho_{0}\left(1-\beta \cdot\left(T_{1}-T_{a m b}\right) \cdot \exp \left(-\frac{h_{L}}{\dot{m} c_{p}} \cdot x\right)\right)
\end{aligned}
$$

Based on the exponential radiator density variation, the thermal driving force in (1) is

$$
\begin{gathered}
p_{T}=\rho_{0} \cdot g \cdot \beta \cdot \Delta T \cdot \Delta H+\left(\rho_{0}-\frac{\rho_{1}+\rho_{2}}{2}\right) \cdot g \cdot L_{r} \\
+g \cdot \rho_{0} \cdot \beta \cdot\left(T_{1}-T_{a m b}\right) \cdot \frac{\dot{m} c_{p}}{h_{L}} \cdot\left(\exp \left(\frac{-h_{L} L_{r}}{\dot{m} c_{p}}\right)-1\right)
\end{gathered}
$$

where $L_{r}$ is the length of the radiator, $\rho_{1}$ is the oil density at the bottom of the winding/radiator, $\rho_{2}$ is the oil density at the top of the winding/radiator. Comparing to (2), (6) has two extra terms to account for the influence of heat transfer coefficient, the mass flow rate and the length of the radiator on the driving force.

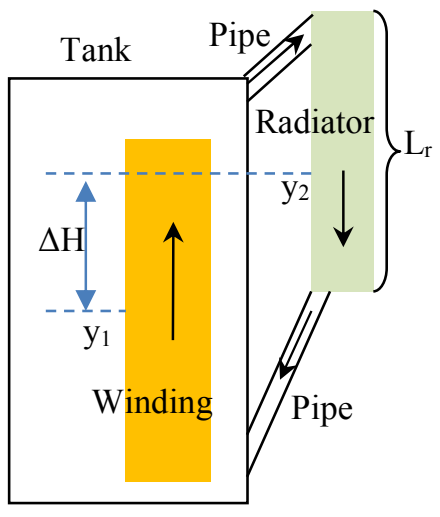

(a)

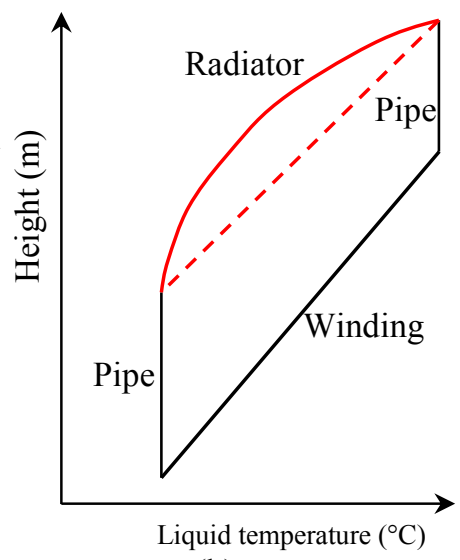

(b)
Fig. 1. Thermal driving force in the loop. (a) Schematic illustration of flow in an $\mathrm{ON}$ transformer. (b) Temperature distribution in the loop.

\section{B. Pressure Drop}

When the minor pressure losses due to change of flow directions are ignored, the pressure drop in the loop can be expressed as:

$$
p_{D}=\frac{C}{\operatorname{Re}} \frac{L^{\prime}}{H^{\prime}} \frac{\rho u_{m}^{2}}{2}
$$

where $C$ is a geometry related constant, $L^{\prime}$ and $H^{\prime}$ are the equivalent length and the equivalent diameter of the circulation loop, respectively, $\rho$ is oil average density, and $u_{m}$ is the average oil velocity at the winding pass inlet.

\section{Liquid Properties}

The liquids investigated are a traditional hydrocarbon mineral oil, a hydrocarbon gas-to-liquid (GTL) oil, a synthetic ester and a natural ester. The properties are functions of temperature in Kelvin obtained by leastsquare curve fitting of the measured data provided by the liquid manufacturers. 


$$
\left\{\begin{array}{l}
\rho_{1}=-0.6568 \times \mathrm{T}+1064\left[\mathrm{~kg} / \mathrm{m}^{3}\right] \\
\mu_{1}=7.863 \times 10^{-5} \times \exp (632.0 /(\mathrm{T}-176.0))[\mathrm{Pa} \cdot \mathrm{s}] \\
\left.\mathrm{c}_{\mathrm{p} 1}=3.950 \times \mathrm{T}+560[\mathrm{~J} / \mathrm{kg} \cdot \mathrm{K})\right] \\
k_{1}=-7.837 \times 10^{-5} \times \mathrm{T}+0.1557[\mathrm{~W} /(\mathrm{m} \cdot \mathrm{K})] \\
\bar{\beta}_{1}=7.778 \times 10^{-4}[1 / \mathrm{K}] \\
\rho_{2}=-0.6455 \times \mathrm{T}+995.5\left[\mathrm{~kg} / \mathrm{m}^{3}\right] \\
\mu_{2}=6.133 \times 10^{-5} \times \exp (749.8 /(\mathrm{T}-157.4))[\mathrm{Pa} \cdot \mathrm{s}] \\
\mathrm{c}_{\mathrm{p} 2}=4.449 \times \mathrm{T}+871.7[\mathrm{~J} /(\mathrm{kg} \cdot \mathrm{K})] \\
k_{2}=-8.217 \times 10^{-5} \times \mathrm{T}+0.1674[\mathrm{~W} /(\mathrm{m} \cdot \mathrm{K})] \\
\bar{\beta}_{2}=8.273 \times 10^{-4}[1 / \mathrm{K}] \\
\rho_{3}=-0.7327 \times \mathrm{T}+1185\left[\mathrm{~kg} / \mathrm{m}^{3}\right] \\
\mu_{3}=6.239 \times 10^{-5} \times \exp (914.1 /(\mathrm{T}-162.4))[\mathrm{Pa} \cdot \mathrm{s}] \\
\mathrm{c}_{\mathrm{p} 3}=2.069 \times \mathrm{T}+1287[\mathrm{~J} /(\mathrm{kg} \cdot \mathrm{K})] \\
k_{3}=-1.236 \times 10^{-4} \times \mathrm{T}+0.1817[\mathrm{~W} /(\mathrm{m} \cdot \mathrm{K})] \\
\bar{\beta}_{3}=7.790 \times 10^{-4}[1 / K] \\
\rho_{4}=-0.6721 \times \mathrm{T}+1118\left[\mathrm{~kg} / \mathrm{m}^{3}\right] \\
\mu_{4}=6.280 \times 10^{-5} \times \exp (1162.1 /(\mathrm{T}-126.48))[\mathrm{Pa} \cdot \mathrm{s}] \\
\mathrm{c}_{\mathrm{p} 4}=5.958 \times \mathrm{T}+170.1[\mathrm{~J} /(\mathrm{kg} \cdot \mathrm{K})] \\
k_{4}=-2.043 \times 10^{-4} \times \mathrm{T}+0.2216[\mathrm{~W} /(\mathrm{m} \cdot \mathrm{K})] \\
\bar{\beta}_{4}=7.517 \times 10^{-4}[1 / \mathrm{K}]
\end{array}\right.
$$

where the subscript 1 is for the mineral oil, 2 for the GTL oil, 3 for the synthetic ester, 4 for the natural ester, and $T$ for temperature in Kelvin.

\section{Flow Rate Ratios}

Once the temperature profile of oil in the radiator is determined, the total liquid flow rate can be obtained by equalizing the thermal driving force to the pressure drop and applying energy conservation to determine the temperature gradient over the winding/radiator.

\section{a) Linear Radiator Oil Temperature Variation}

The total liquid flow rate in terms of winding pass inlet velocity is determined as [4]:

$u_{m}^{2}=C_{g} \frac{\rho_{0} g \beta}{\mu \rho c_{p}} \Delta H \cdot P$

where $C_{g}$ is a constant related to transformer geometry. For ON transformer retrofilling scenarios, the differences introduced are different liquid properties. Based on the properties in (8), the total flow rate ratios for the mineral oil (MO), the GTL oil, the synthetic ester (SE) and the natural ester (NE) for different liquid average temperatures are shown in Table 1 with reference temperature setting to be $20{ }^{\circ} \mathrm{C}$. Table 1 shows that the flow rate ratios are quite constant for a practical liquid temperature range.
TABLE 1. FLOW RATE RATIOS FOR DIFFERENT LIQUIDS AT DIFFERENT TEMPERATURES

\begin{tabular}{|c|c|c|c|c|}
\hline Temperature $\left({ }^{\circ} \mathrm{C}\right)$ & $\mathrm{MO}$ & $\mathrm{GTL}$ & $\mathrm{SE}$ & NE \\
\hline 20 & 1 & 0.97 & 0.48 & 0.48 \\
\hline 40 & 1 & 0.94 & 0.52 & 0.47 \\
\hline 60 & 1 & 0.92 & 0.56 & 0.47 \\
\hline 80 & 1 & 0.92 & 0.60 & 0.48 \\
\hline
\end{tabular}

b) Exponential Radiator Oil Temperature Profile

When the exponential radiator oil temperature is used to determine the thermal driving force as shown in (6), the total liquid flow rate ratios can no longer be determined without detailed transformer geometric information. It is supposed to give more accurate flow rate estimation.

\section{QUANTIFICATION OF MiNOR PRESSURE LOSSES}

\section{A. Establishment of Winding Hydraulic Model}

To quantify the percentage of "minor losses" in the total pressure loss, a hydraulic network model for disc-type transformer windings is established. The methodology of establishing the network model follows closely to that presented in [9].

To check the validity of the network model established, comparisons of liquid flow distributions and pressure drop over the winding are made among results from the established model, results from [9] and results from a computational fluid dynamics (CFD) model. The benchmark winding is a planar 2D 1-pass winding model, of which the most prominent feature is the halved top horizontal duct height. Details of the winding can be found in [9]. The flow distribution and total pressure drop $(\Delta p)$ over the winding comparisons are shown in Fig. 2 and Table 2, respectively. The established winding hydraulic network model generates results that are comparable to the results from CFD and the model from [9].

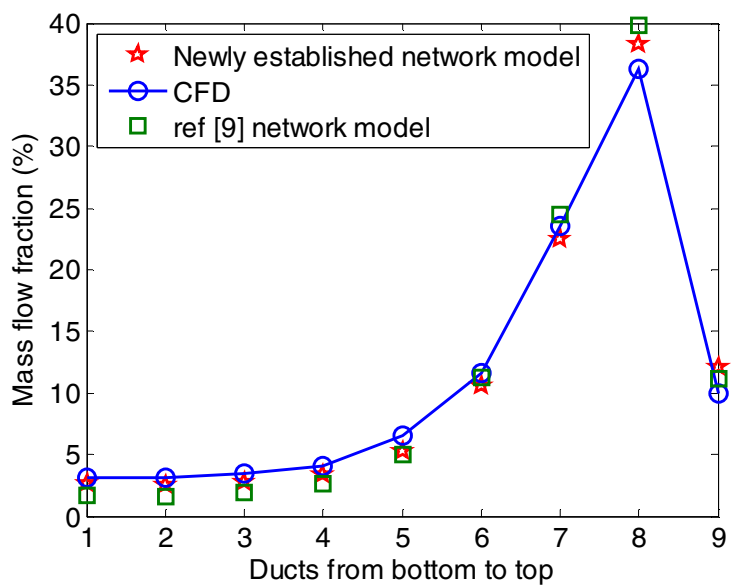

Fig. 2. Comparison of flow distributions.

TABLE 2. TOTAL PRESSURE LOSS COMPARISONS

\begin{tabular}{|c|c|c|c|}
\hline & Newly established model & Ref [9] model & CFD \\
\hline$\Delta \mathrm{p}(\mathrm{Pa})$ & 278.51 & 263.56 & 275.35 \\
\hline
\end{tabular}

\section{B. Minor Loss Percentage}

With the hydraulic network model developed, the percentage of "minor losses" in the total pressure loss of a typical winding can be investigated conveniently. The winding investigated is a planar 2D 1-pass disc-type 
winding with 10 discs/11 ducts with detailed geometric dimensions shown in Fig. 3.

For ON transformers $R e$ at the winding pass inlet ranges approximately from 50 to 200 . Pressure drop over the winding is identical whatever the flow path is chosen. However, the "Minor Loss" Percentage (MLP) differs for different paths chosen. 11 flow paths are chosen with each going through a horizontal duct. Path 1 goes through the bottom horizontal duct and sequentially path 11 goes through the top horizontal duct. MLP in each path for different $R e$ 's are shown in Fig. 4. Figure 4 shows that MLP is higher for paths going through bottom horizontal ducts and it increases with the increase of $R e$. For paths going through top horizontal ducts, MLP can be negative, caused by some negative "minor losses".

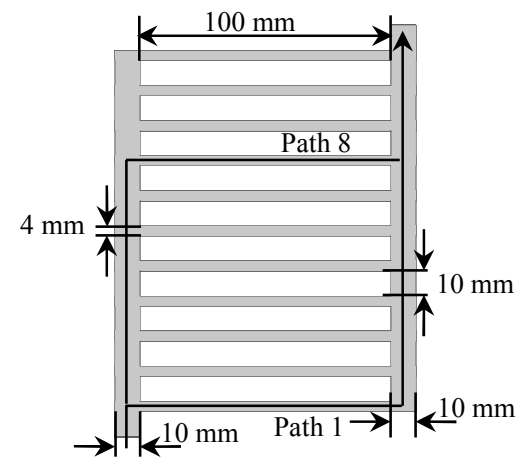

Fig. 3. Investigated 1-pass disc-type winding.

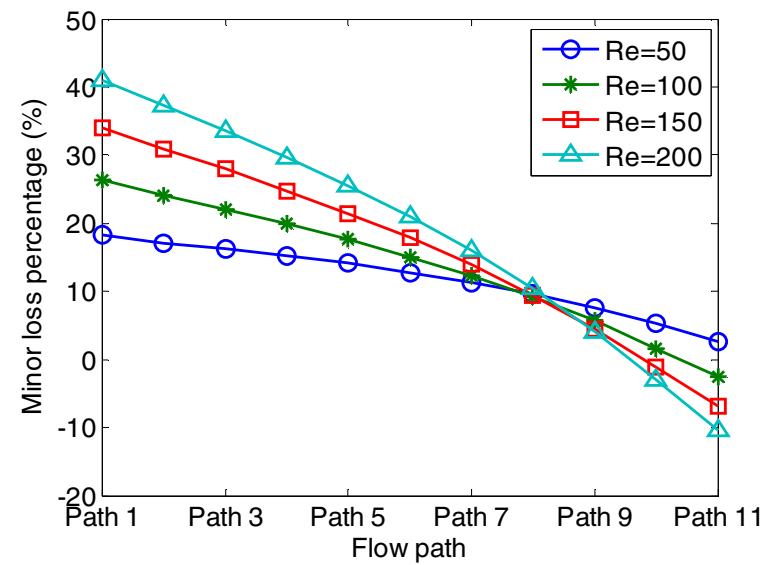

Fig. 4. Minor loss percentage for different paths and different $R e$ 's.

In the hydraulic network model, the "minor losses" can be eliminated. Then the total pressure loss is purely due to major losses (friction losses). This major-loss-only total pressure drop can be treated as the major loss in cases considering "minor losses". MLP in this regard for different $R e$ 's are shown in Table 3. Table 3 shows that MLP increases with $R e$ and it is indeed minor.

TABLE 3. PERCENTAgE OF MINOR LOSS IN TOTAL PRESSURE LOSS

\begin{tabular}{|c|c|c|c|c|}
\hline & $\mathrm{Re}=50$ & $\mathrm{Re}=100$ & $\mathrm{Re}=150$ & $\mathrm{Re}=200$ \\
\hline MLP (\%) & 11.7 & 13.7 & 16.0 & 18.5 \\
\hline
\end{tabular}

The pressure loss results in Fig. 4 and Table 3 are for the winding geometry investigated in isothermal conditions. We regard these results as representative because pressure losses are mainly dictated by the total flow rate and the winding geometry is more complex than the radiator and pipework leading to a higher MLP in the winding, so MLP in the whole cooling loop is lower. Further study considering the effect of heat transfer and flow in radiators and pipework can be implemented to conform it.

\section{CONCLUSION}

Total liquid flow rates for $\mathrm{ON}$ transformer retrofilling scenarios have been investigated theoretically. The flow rate ratios of different liquids can be obtained directly but less accurately when the oil temperature variation in the radiator is treated linear. When the ambient temperature and heat transfer coefficient on the radiator surface are assumed constant, an exponential radiator oil temperature variation is obtained. Based on the exponential radiator oil temperature variation and detailed transformer geometric information, more accurate flow rate estimations are expected. Finally, the percentage of "minor losses" in the total pressure loss for $\mathrm{ON}$ transformer flow conditions is proved to be indeed minor, justifying neglecting the minor losses in the deduction of the total liquid flow rate.

\section{ACKNOWLEDGMENT}

The authors would like to express their gratitude to Cargill, EPRI, M\&I Materials, National Grid, Scottish Power, Shell, SGB-SMIT, TJ|H2b Analytical Services, and Weidmann Electrical Technology AG for their financial and technical contributions to the Transformer Research Consortium at The University of Manchester.

\section{REFERENCE}

[1] IEC, "Loading guide for oil-immersed power transformers," in IEC standard 60076-7, ed, 2018.

[2] IEEE, "IEEE Guide for Loading Mineral-Oil-Immersed Transformers and Step-Voltage Regulators," in IEEE standard C57.91, ed, 2011.

[3] X. Zhang, Z. D. Wang, Q. Liu, P. Jarman, A. Gyore, and P. Dyer, "Numerical investigation of influences of coolant types on flow distribution and pressure drop in disc type transformer windings," presented at the International Conference on Condition Monitoring and Diagnosis (CMD), 2016, Xi'an, P.R. China, 2016.

[4] X. Zhang, Z. Wang, Q. Liu, M. Negro, A. Gyore, and P. W. R. Smith, "Numerical Investigation of Influences of Liquid Types on Flow Distribution and Temperature Distribution in Disc Type ON Cooled Transformers," presented at the The 19th IEEE International Conference on Dielectric Liquids (ICDL), Manchester, UK, 2017.

[5] M. Daghrah, X. Zhang, Z. Wang, Q. Liu, P. Jarman, and D. Walker, "Experimental and Numerical Investigation of Flow and Temperature Distributions in Disc Type Transformer Windings-Part I: Forced and Directed Cooling Modes," IEEE Transactions on Power Delivery, Under review, 2019.

[6] M. Daghrah, Z. Wang, Q. Liu, A. Hilker, and A. Gyore, "Experimental Study of the Influence of Different Liquids on the Transformer Cooling Performance," IEEE Transactions on Power Delivery, In Press, 2018.

[7] M. Yamaguchi, T. Kumasaka, Y. Inui, and S. Ono, "The flow rate in a self-cooled transformer," IEEE Transactions on Power Apparatus and Systems, pp. 956-963, 1981.

[8] I. Lokhmanets and B. R. Baliga, "Experimental Investigation of a Simplified Model of a Transformer Cooling System," in ASME 2017 Power Conference, 2017, pp. V002T12A004V002T12A004.

[9] J. Coddé, W. Van der Veken, and M. Baelmans, "Assessment of a hydraulic network model for zig-zag cooled power transformer windings," Applied Thermal Engineering, vol. 80 , pp. 220-228, 2015. 